\title{
Morfometria, aspectos de qualidade físico-química e microbiológica da água e ações antrópicas em bacia hidrográfica na região de Mata Atlântica, Brasil
}

\author{
Morphometry, physical-chemical and microbiological water quality aspects and anthropic actions \\ in a watershed in the Atlantic Forest region, Brazil \\ Morfometría, aspectos físico-químicos y microbiológicos de la calidad del agua y acciones \\ antrópicas en una cuenca hidrográfica de la región de la Mata Atlántica, Brasil
}

\begin{tabular}{|c|}
\hline 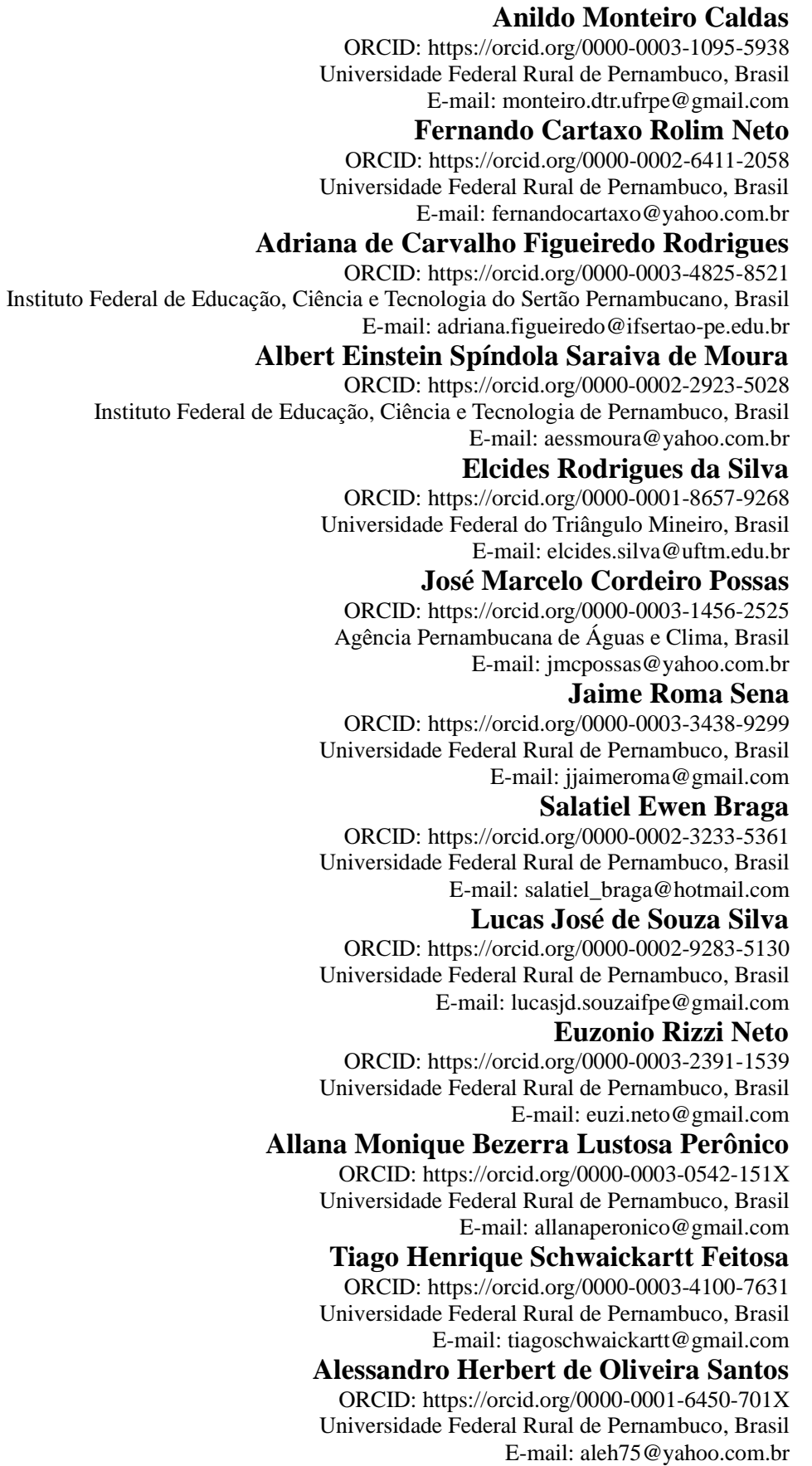 \\
\hline
\end{tabular}


Ioneide Alves de Souza

ORCID: https://orcid.org/0000-0001-5144-8444 Universidade Federal Rural de Pernambuco, Brasil E-mail: ioneide_clima@yahoo.com.br

Marcus Metri Corrêa

ORCID: https://orcid.org/0000-0002-9506-8969 Universidade Federal Rural de Pernambuco, Brasil E-mail: marcus.metri@gmail.com

\begin{abstract}
Resumo
Considerado um ecossistema complexo, a Mata Atlântica detém uma das maiores biodiversidades do planeta. Estudos em bacias hidrográficas inseridas neste ecossistema são relevantes para entender seu funcionamento hidrológico, visando o monitoramento da quantidade e qualidade da água decorrentes do uso dos recursos naturais. Por sua vez, as características morfométricas, físico-químicas e microbiológicas da água em bacias hidrográficas foram de grande interesse para compor o objeto deste estudo, visto que a qualidade deste serviço ambiental reflete diretamente na saúde da população e ao sistema aquático. A presente pesquisa foi conduzida na microbacia do Prata, situada dentro dos limites do Parque Estadual Dois Irmãos, um remanescente de Mata Atlântica, localizado na Região Metropolitana do Recife (RMR). Com o objetivo de caracterizar a morfometria e relacionar aspectos físico-químicos e microbiológicos da água com as ações antrópicas atuantes sobre a microbacia do Prata, verificou-se que a rede de drenagem é de $4^{\mathrm{a}}$ ordem e apresentar tendência baixa à enchentes e se estas ocorrerem, poderão ser de médio a grande porte. Há o predomínio da classe de 20 - 45\% de declividade, totalizando quase $50 \%$ da área da microbacia. Durante o período monitorado a qualidade das águas os dois reservatórios se encontraram fora dos padrões de potabilidade, sendo necessário tratamento de desinfecção para seu consumo. Faz-se necessário a tomada de medidas de proteção e educação ambiental das comunidades ao entorno, visando mitigar o avanço da pressão antrópica sobre a área da microbacia do Prata.
\end{abstract}

Palavras-chave: Segurança hídrica; Serviço ambiental; SIG; Florestas urbanas.

\begin{abstract}
Considered a complex ecosystem, the Atlantic Forest holds one of the largest biodiversities on the planet. Studies in watersheds inserted in this ecosystem are relevant to understand its hydrological functioning, aiming to monitor the quantity and quality of water arising from the use of natural resources. In turn, the morphometric, physicochemical, and microbiological characteristics of the water in watersheds were of great interest to compose the object of this study, since the quality of this environmental service reflects directly on the health of the population and the aquatic system. The current research was conducted in the Prata watershed, situated within the limits of the Dois Irmãos State Park, a remnant of the Atlantic Forest, located in the Metropolitan Region of Recife (RMR). In order to characterize the morphometry and relate physical-chemical and microbiological aspects of the water with the anthropic actions acting on the Prata watershed, it was verified that the drainage network is of 4th order and presents a low tendency to flooding and if they occur they can be of medium to large size. There is a predominance of the $20-45 \%$ slope class, totaling almost $50 \%$ of the micro-basin area. During the monitored period the quality of the water in the two reservoirs was outside the potability standards, requiring disinfection treatment for consumption. It is necessary to take measures of protection and environmental education of the surrounding communities in order to mitigate the advance of anthropic pressure on the Prata watershed area.
\end{abstract}

Keywords: Water security; Environmental services; SIG; Urban forests.

\title{
Resumen
}

Considerado un ecosistema complejo, el Bosque Atlántico alberga una de las mayores biodiversidades del planeta. Los estudios en las cuencas hidrográficas insertas en este ecosistema son relevantes para entender su funcionamiento hidrológico, con el objetivo de monitorear la cantidad y calidad del agua derivada del uso de los recursos naturales. A su vez, las características morfométricas, fisicoquímicas y microbiológicas del agua en las cuencas hidrográficas fueron de gran interés para componer el objeto de este estudio, ya que la calidad de este servicio ambiental se refleja directamente en la salud de la población y del sistema acuático. La presente investigación se llevó a cabo en la cuenca hidrográfica de Prata, situada dentro de los límites del Parque Estatal de Dois Irmãos, un remanente de bosque atlántico situado en la Región Metropolitana de Recife (RMR). Con el objetivo de caracterizar la morfometría y relacionar los aspectos físico-químicos y microbiológicos del agua con las acciones antrópicas que actúan sobre la cuenca hidrográfica de Prata, se verificó que la red de drenaje es de $4^{\mathrm{a}}$ orden y presenta baja tendencia a las inundaciones y si éstas ocurren, pueden ser de mediano a gran tamaño. Predomina la clase de pendiente del 20-45\%, que totaliza casi el 50\% del área de la microcuenca. Durante el periodo supervisado, la calidad del agua de los dos embalses estaba fuera de las normas de potabilidad, lo que requería un tratamiento de desinfección para su consumo. Es necesario tomar medidas de protección y educación ambiental en las comunidades aledañas para mitigar el avance de la presión antrópica en la zona de la cuenca de Prata.

Palabras clave: Seguridad hídrica; Servicios medioambientales; SIG; Bosques urbanos. 


\section{Introdução}

A Mata Atlântica é um ecossistema complexo, considerado um dos mais biodiversificados do planeta e um dos cinco mais importantes do mundo. (Rodrigues, Moreira \& Freire, 2021).

Estudos em bacias hidrográficas inseridas neste ecossistema são importantes para entender seu funcionamento hidrológico e a interação com o meio ambiente, visando o monitoramento da quantidade e da qualidade da água decorrentes do uso dos recursos naturais para subsidiar a geração de políticas públicas sobre o uso e conservação de solo e água (Braga et al., 2020, 2021).

As bacias hidrográficas têm sido utilizadas como uma unidade geomorfológica fundamental. Isso se deve ao fato de suas características governarem, no seu interior, todo o fluxo superficial da água. Assim, vem sendo considerada uma unidade territorial ideal para o planejamento integrado do manejo dos recursos naturais (Pissarra et al., 2004).

Christofoletti (1970), afirma que para se entender o funcionamento de uma bacia, torna-se necessário expressar quantitativamente as manifestações de forma (área, forma geométrica, etc.), de processo (escoamento, deflúvio, etc.) e suas inter-relações. Essas manifestações denominadas de caracterização morfométrica objetiva obter índices quantitativos, os quais auxiliam os estudos hidrológicos de uma bacia hidrográfica (Silva et al., 2016). Os parâmetros morfométricos são reconhecidos na literatura como importante fonte de informação para o conhecimento das características físicas das bacias, bem como para interpretação de sua dinâmica geomorfológica (Khanday \& Javed, 2017; Leal \& Tonello, 2017; Sreedevi et al., 2013).

Além das características morfometrias, o estudo das características físico-químicas e microbiológicas da água em bacias hidrográficas é de grande importância uma vez que a qualidade deste serviço ambiental reflete diretamente na saúde da população. Para Gonçalves et al. (2005), qualidade de água está relacionada ao tipo de uso e envolve a avaliação das suas condições físicas, químicas e biológicas, relacionando-se à sua potencialidade, quanto a causar danos à saúde humana e ao sistema aquático.

O Brasil possui a maior disponibilidade de água potável, com cerca de $11 \%$ do total mundial. Contudo, a distribuição deste recurso no território nacional não se faz de forma homogênea, sendo a região Nordeste a que mais sofre com os problemas de escassez de água (Correa, Fernandes, \& Santana, 2020).

Os recursos hídricos são um elemento-chave nas políticas de combate à pobreza, mas por vezes são ameaçados pelo próprio desenvolvimento. A água influencia diretamente o nosso futuro, fazendo-se necessário mudanças na forma como avaliamos, gerenciamos e usamos esse recurso, em face da crescente demanda e da grande exploração das reservas deste serviço ambiental (UNESCO, 2016).

As atividades antrópicas que afetam os ciclos hidrológicos, a disponibilidade de água e o acesso à água têm se intensificado com as transformações dos ambientes naturais em sistemas agrícolas têm provocado a degradação dos solos, principalmente por meio da compactação do solo, redução da atividade biológica e consequente perda de nutrientes e matéria orgânica por erosão (Bagatini et al., 2011; Moraes et al., 2012; Boldaji \& Kellerb, 2016). Os ciclos hidrológicos são afetados pelas mudanças naturais e por aquelas produzidas pelo homem, como, por exemplo, o uso excessivo dos aquíferos para abastecimento ou irrigação e a supressão das florestas nativas (Vörösmarty et al., 2010; Young et al., 2014).

Assim, a preservação associada à melhoria da qualidade de vida e ao equilíbrio do meio ambiente urbano, as chamadas florestas urbanas, em sua maioria remanescentes de biomas como a Mata Atlântica, podem ser definidas como a soma de toda a vegetação lenhosa que se envolve dentro de um aglomerado urbano independente de suas dimensões (Silva, Fontes \& Faria, 2019). Este ecossistema é composto pela interação entre os sistemas naturais e os sistemas antropogênicos (Silva et al., 2019).

Considerando o ambiente como um sistema composto por variáveis distribuídas no espaço e no tempo, o mesmo deve 
ser estudado a partir de modelos que permitam representar a territorialidade e a inspeção de possíveis relacionamentos entre essas variáveis. Para tanto, a representação digital do ambiente tem se mostrado extremamente útil (Christofoletti, 1999).

Dependendo do interesse do usuário, estas correlações permitem o equacionamento de situações ambientais, tais como o levantamento de áreas de risco e estimativas de impactos ambientais, definição de unidades e normas de manejo e zoneamento territorial gerando conhecimentos indispensáveis para a utilização racional dos recursos ambientais disponíveis (Moraes, 1993).

Neste contexto, inserida dentro do município do Recife, encontra-se a Reserva Ecológica de Dois Irmãos, com os açudes dos Macacos, do Meio, do Prata e de Dois Irmãos, compondo a microbacia hidrográfica do Prata. Ao longo dos anos os açudes vêm contribuindo para o abastecimento da cidade do Recife de maneira muito reduzida, devido ao aumento da demanda d'água.

O objetivo deste trabalho foi realizar as caracterizações morfométrica, dos aspectos físico-químicos e biológicos e das ações antrópicas na microbacia do Prata.

\section{Metodologia}

\section{Área de estudo}

Compreende a microbacia do Prata, localizada geograficamente entre os vértices $07^{\circ} 59^{\prime} 58^{\prime \prime}$ / $34^{\circ} 56^{\prime} 23^{\prime \prime}$ e $08^{\circ} 01^{\prime}$ 02" / $34^{\circ} 57^{\prime}$ 27', na Zona da Mata do estado de Pernambuco, na região metropolitana do Recife (Figura 1), dentro dos limites do Parque Estadual Dois Irmãos. Apresenta uma área de 196,0 hectares, dos quais 5,5\% são espelho d'água, e corresponde a aproximadamente 50\% dos 387,4 hectares do Parque Estadual Dois Irmãos (RECIFE, 2000).

O clima, segundo a classificação de Köppen, é do tipo As', quente e úmido, com temperatura mínima de $18{ }^{\circ} \mathrm{C}$, médias mensais superiores a $23{ }^{\circ} \mathrm{C}$, mas com pequena amplitude térmica e precipitação média anual em torno dos $2.460 \mathrm{~mm}$ (Coutinho et al., 1998).

Figura 1. Localização da microbacia do Prata no estado de Pernambuco.

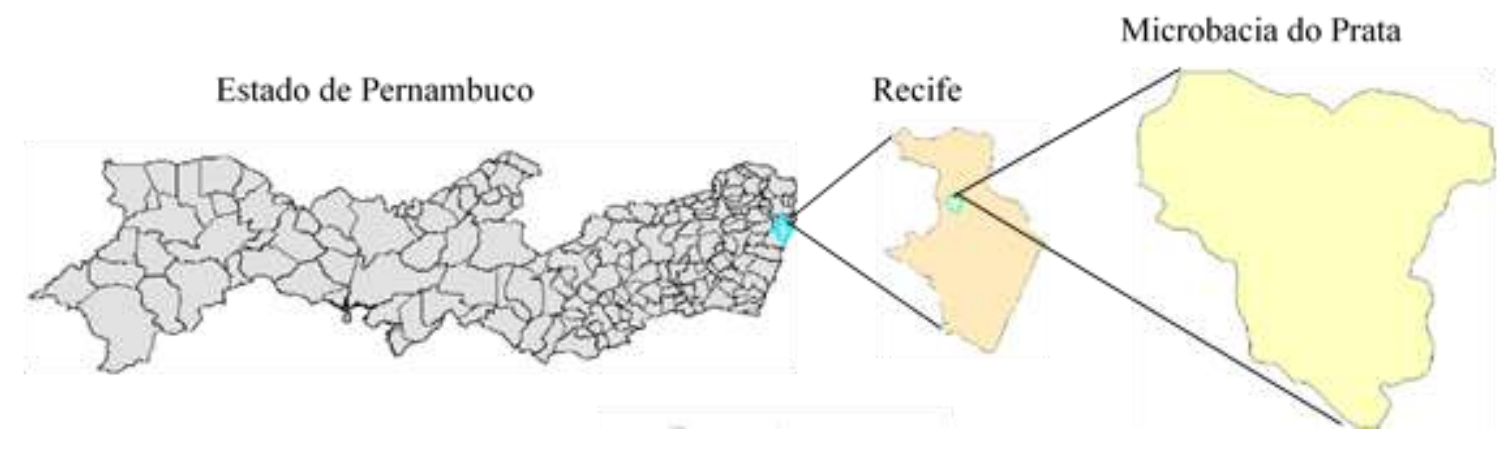

Fonte: Autores.

\section{Banco de dados e modelagem digital}

Os dados espaciais foram armazenados em formato digital para processamento em sistema de informação geográfica. A modelagem digital da microbacia do Prata foi feita com base em oito ortofotocartas, no formato digital e impresso, da cidade do Recife (Figura 2), resultantes da restituição e retificação de fotografias aéreas do ano de 1974, oriundas da Agência Estadual de Planejamento e Pesquisas (CONDEPE/FIDEM), todas em escala de 1:2.000, projeção UTM, datum SAD 69 e com dois metros de equidistância entre as curvas de nível, em formato digital. 
Figura 2. Ortofotocartas utilizadas na delimitação da bacia com seus respectivos índices catalográficos da mapoteca.

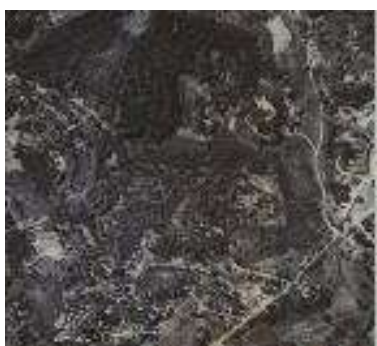

8143

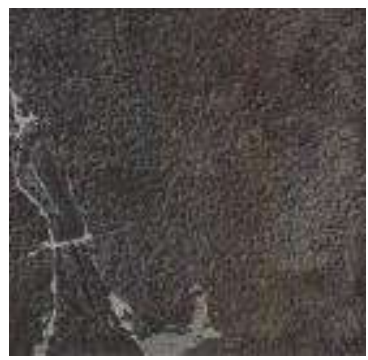

8154

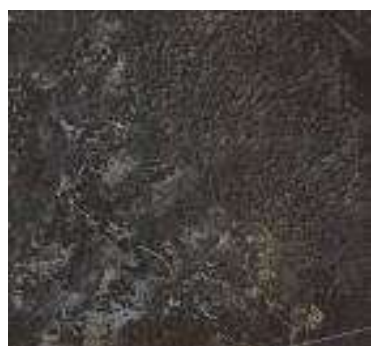

8144

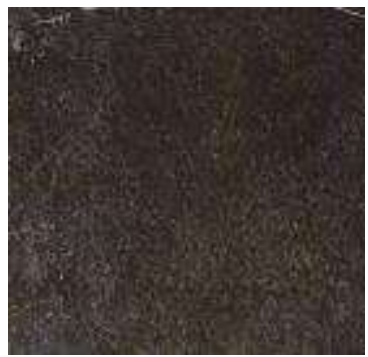

8155

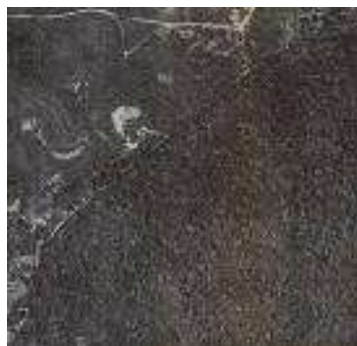

8145

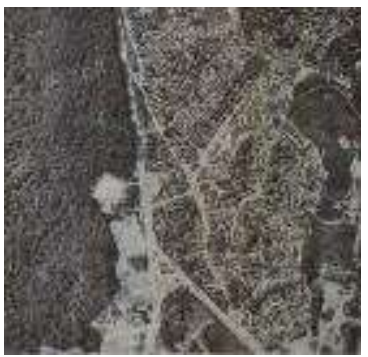

8164

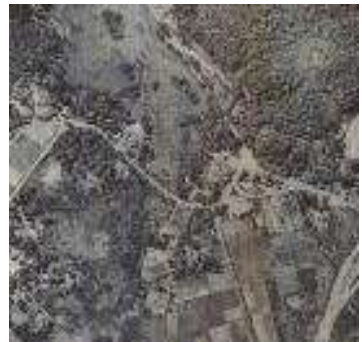

8153

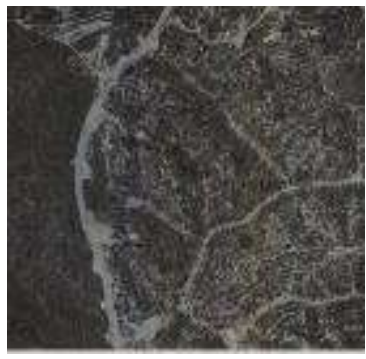

8165

Fonte: CONDEPE/FIDEM.

A modelagem digital foi realizada no software ArcGIS da ESRI GIS and Mapping Software, licenciado para o laboratório de Geotecnologias (GEOLab) do Departamento de Tecnologia Rural da UFRPE. O módulo ArcCatalog foi utilizado para criação de uma plataforma GeodataBase, denominada BACIA_DO_PRATA, para armazenamento e organização dos dados e mapas temáticos obtidos.

O mosaico de ortofotocartas foi obtido no módulo ArcMap, a partir da inserção das coordenadas de controle, sobre o qual vetorizou-se os pontos cotados e as curvas de nível que serviram para a delimitação da microbacia do Prata, obtendo-se os arquivos em formato shapefile.

De posse dos arquivos shapefiles limites, curvas de nível e pontos cotados, procederam-se à confecção do Triangular Irregular Network (TIN), que serviu como base para a geração do modelo digital de elevação (MDE).

\section{Caracterização morfométrica da microbacia}

As características morfométricas perímetro (P), área (A), limite, rede de drenagem foram obtidos de forma digital com o auxílio da extensão Hydrology do ArcGIS. Neste estudo utilizou-se a classificação apresentada por Strahler (1957), em que para cursos d'água sem tributários é adotada a ordem "1", ou primeira ordem. Cursos d'água denominados de segunda ordem são aqueles que recebem somente tributários de primeira ordem, independentemente do número de tributários. De terceira ordem são aqueles que recebem dois ou mais tributários de segunda ordem, podendo também receber tributários de primeira ordem, e assim sucessivamente

A densidade de drenagem (Dd) foi obtida através da relação entre o comprimento da rede e a área de drenagem, expressa em $\mathrm{km} / \mathrm{km}^{2}$. 
A forma da bacia foi avaliada utilizando os seguintes índices: coeficiente de compacidade (Kc, equação 1), fator de forma (Ff, equação 2) e índice de circularidade (Ic, equação 3). onde $\mathrm{P}=$ perímetro da bacia; $\mathrm{A}=$ área da bacia e $\mathrm{L}=$ comprimento da bacia

$$
\begin{array}{ccc}
\text { Equação } 1 & P & \text { Equação } 2 \\
F_{f}=\frac{A}{L^{2}} & \text { Equação } 3
\end{array}
$$

A declividade de álveo ou declividade do canal (Ieq, Equação 4) foi calculado pelo método da média harmônica, o mais usual para se determinar a declividade do álveo. Onde L é a extensão do talvegue principal, que é dividido em $n$ trechos, sendo Li e Ii, respectivamente, a extensão horizontal e a declividade média em cada trecho. Já para calcular o tempo de concentração (Tc, Equação 5) foi utilizada a fórmula de Ven Te Chow. em que Tc é expresso em minutos; L em km e Ieq em $\mathrm{m} / \mathrm{km}$.

$$
\begin{gathered}
\text { Equação-4ๆ } \\
I_{\text {eq }}=\left[\frac{L}{\sum_{i=1}^{n} \frac{L}{\sqrt{I}}}\right]^{2} \quad I_{c}=52,64\left(\frac{L}{\sqrt{I_{e q}}}\right)^{0.64}
\end{gathered}
$$

\section{Mapas temáticos}

Foram produzidos quatro mapas temáticos, altimétrico, MDE, declividade e Drenagem. O mapa altimétrico foi construído a partir das ortofotocartas digitais, previamente "escaneadas", tendo suas curvas de nível vetorizadas com o uso do software ArcGIS.

O mapa do MDE foi criado a partir do mapa das curvas de nível, dos pontos cotados existentes nas ortofotocartas e do limite da microbacia.

O mapa de declividade foi criado a partir do MDE e na definição de suas classes foi feita uma adaptação de Embrapa (1988), pois neste trabalho os tipos de relevo referem-se apenas às classes de declividade.

O mapa de drenagem foi gerado no formato digital com o auxílio da extensão Hydrology do ArcGIS, tendo por base o MDE.

\section{Análises físico-químicas e microbiologicas da água}

As amostras de água foram coletadas bimestralmente durante o período de um ano, em dois pontos, na camada superficial de $0-10 \mathrm{~cm}$ de profundidade, nos açudes do Prata e do Meio (Figura 3A e 3B). 
Figura 3. Vista parcial das coletas de água realizadas nos açudes do Prata (A) e do Meio (B).

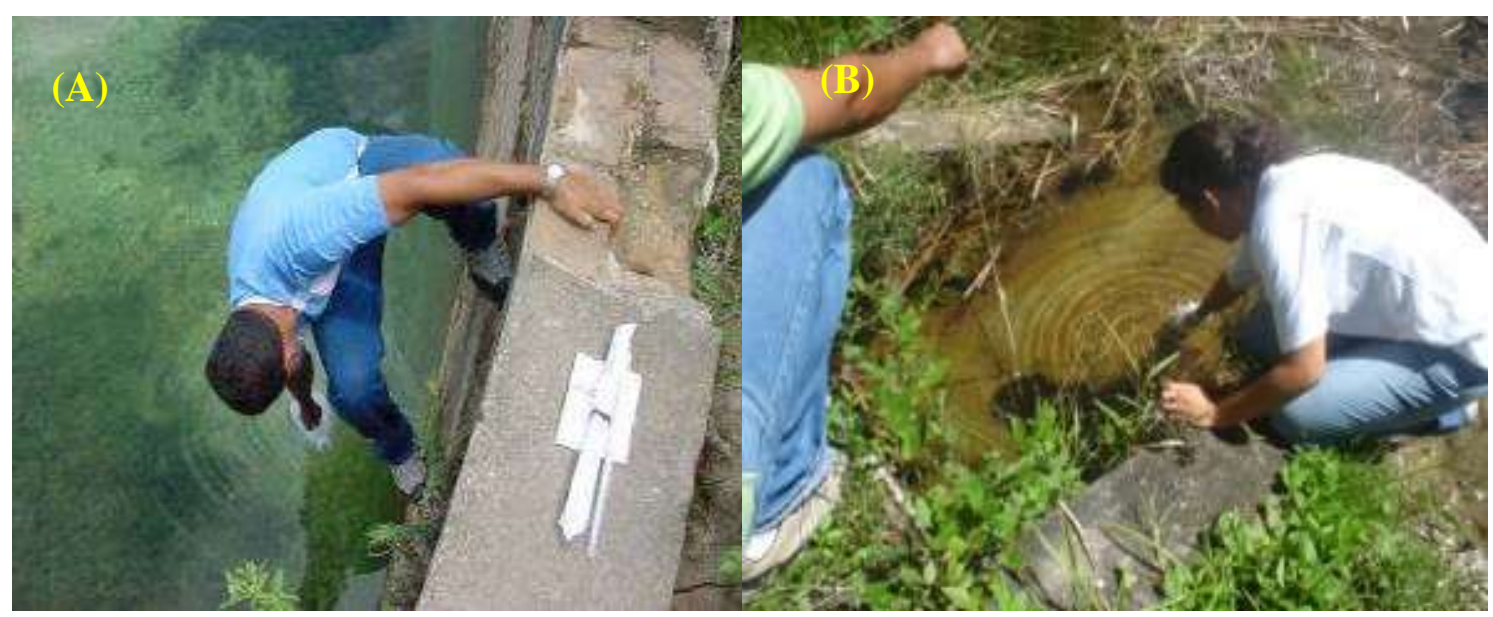

Fonte: Autores.

As amostras foram encaminhadas ao laboratório de Engenharia Ambiental e Química (LEAQ) da UFPE, onde foram realizadas as análises físico-químicas e microbiológicas de potencial hidrogeniônico $(\mathrm{pH})$, oxigênio dissolvido (OD), demanda bioquímica de oxigênio (DBO), coliformes totais (CT) e coliformes fecais (CF).

Para determinar o OD, as amostras foram coletadas em frascos de vidro. Depois de encher o frasco com o devido cuidado para evitar formação de bolhas, adicionou-se $1 \mathrm{~mL}$ da solução de sulfato de manganês e $1 \mathrm{~mL}$ da solução de iodeto alcalino, agitando-se em seguida para homogeneizar. Os frascos foram armazenados em caixa térmica, protegidos da luz.

Para determinar a DBO e pH, foram coletados 2 litros de água em recipientes plásticos esterelizado e posteriormente armazenados em caixa térmica com gelo.

Para as análises de coliformes totais e coliformes fecais, utilizou-se sacos de coleta contendo Etileno-diaminotetracetato de cálcio (EDTA) para inibir metais e Tiossulfato de sódio para inibir o cloro. Posteriormente, foram acondicionadas em caixa térmica As quantificações de coliformes totais e fecais foram feitas através do método de Determinação do Número Mais Provável (NMP) de coliformes pela Técnica dos Tubos Múltiplos.

Todos os procedimentos de coleta, conservação e análise, obedeceram às metodologias descritas no Standard Methods for the Examination of Water and Wastewater, American Public Health Association (APHA, 2005) e os resultados obtidos foram comparados com os padrões estabelecidos pela Resolução CONAMA n³57 de 17 de março de 2005 (CONAMA, 2005).

\section{Resultados e Discussão}

\section{Morfometria}

Com o intuito de se obter a visualização de toda área da microbacia do Prata, foi gerado o mosaico de ortofotocartas digitais (Figura 4) podendo-se perceber a riqueza de detalhes, evidenciando a ocupação do solo, por meio das estradas, da vegetação elevada, com mata densa, dos talvegues principais, dos corpos d'água e, de maneira muito nítida. Pode-se constatar que há uma tonalidade mais escura de cinza, nas áreas com mata densa, particularmente por conta da umidade existente na folhagem. Os pontos que aparecem na Figura 4, com cor laranja, correspondem à plotagem de pontos de controle, existentes nas ortofotocartas em formato analógico, objetivando-se auxiliar o georreferenciamento das ortofotocartas digitais e, 
principalmente, na futura geração do MDE. Constata-se uma densidade maior desses pontos na porção sul da microbacia, possivelmente em virtude da dificuldade em obtê-los nas áreas onde a mata prevalece.

Na Figura 4 pode-se observar o limite e a rede de drenagem, obtidos com auxílio do MDE. Pela sobreposição da rede de drenagem gerada no MDE com aquela existente no mosaico, percebe-se uma coincidência quase perfeita, deduzindo-se daí que a utilização dos pontos de controle foi de grande valia. Quando o MDE foi gerado sem os mesmos, apareceram zonas sem informações. Desta forma o MDE gerado a partir dos arquivos das curvas de nível e pontos cotados pode ser considerado hidrologicamente consistente.

A área obtida foi de 185,58 hectares, que quando comparados aos 196,0 hectares descritos em Recife (2000), constatou-se uma diferença de 10,42 hectares para menos.

Este fato pode ser explicado por conta de diferenças no material cartográfico básico utilizado, software utilizado ou tipo de dado raster e vetorial.

Figura 4. Mosaico construído a partir das ortofotocartas com delimitação da bacia hidrográfica, rede de drenagem e pontos de controle.

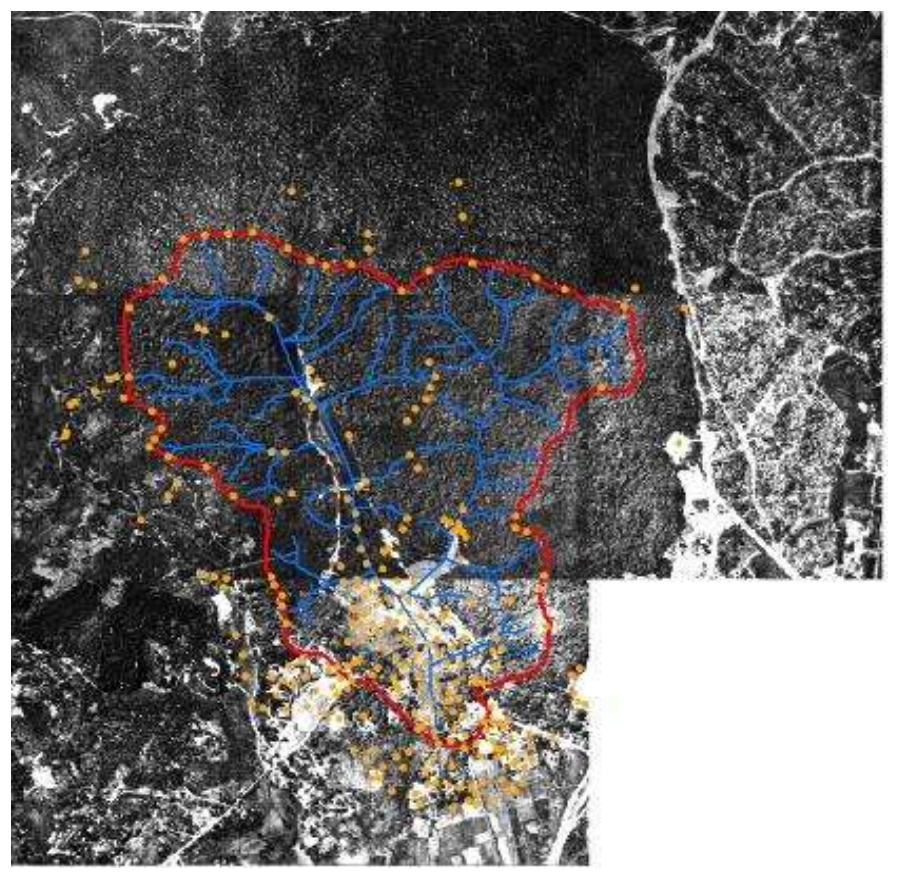

Fonte: Autores.

Na Figura 5, evidencia-se as curvas de nível juntamente com os pontos de controle e o limite da microbacia, apesar de existir influência de sedimentos recentes nos terrenos das partes mais baixas dos talvegues, a microbacia encontra-se no contexto dos sedimentos do Grupo Barreiras, com altitudes que variam de 8 a 104 metros, a cota mínima está localizada próximo do açude dos macacos e a máxima na borda nordeste do limite da microbacia, configurando uma altitude média de 53 m e amplitude altimétrica de $96 \mathrm{~m}$. Santos et al. (2012) consideram de alta importância essa característica fisiográfica de bacias, uma vez que está relacionada a vulnerabilidade de evaporação da água no solo em decorrências da maior ou menor incidência de energia na área. 
Figura 5. Mapa altimétrico evidenciando os açudes, pontos de controle e a delimitação da microbacia do Prata.

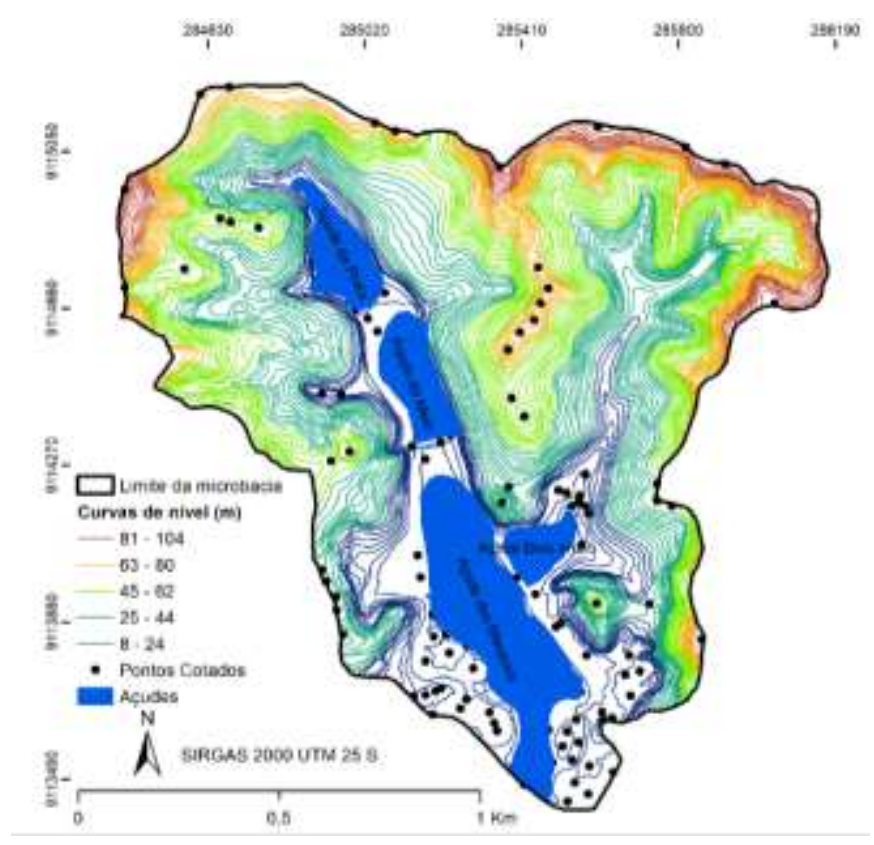

Fonte: Autores.

Duarte et al. (2007) afirmam que a temperatura média de uma bacia está diretamente relacionada a altitude média e variação da altitude. Além de promover alterações significativas na temperatura média da bacia, as variações de elevação também provocam alterações significativas na precipitação média anual (Fraga et al., 2014).

De uma maneira geral, percebe-se que as curvas de nível estão coerentes com o modelado do terreno onde os menores valores, representam os espelhos d'água dos açudes do Prata, do Meio, Dois Irmãos e dos Macacos, que juntos somam uma área de 22,57 ha. Estes apresentam-se, respectivamente, numa sequência do maior para o menor valor de altitude, evidenciando que ocorre um fluxo natural de escoamento por conta da diferença de nível existente. Para Ferreira, Franco e Souza (2020), a vulnerabilidade a erosão e os impactos na qualidade da água podem ser agravados pela relação entre as altas amplitudes altimétricas e declividade, o tipo de solo e o manejo empregado na bacia.

No MDE gerado (Figura 6), pode-se constatar a congruência com o mapa altimétrico da Figura 5, ao mesmo tempo em que permite uma melhor visualização do relevo por conta do estabelecimento de 9 classes de altitudes. 
Figura 6. Mapa do modelo digital do terreno da microbacia do Prata.

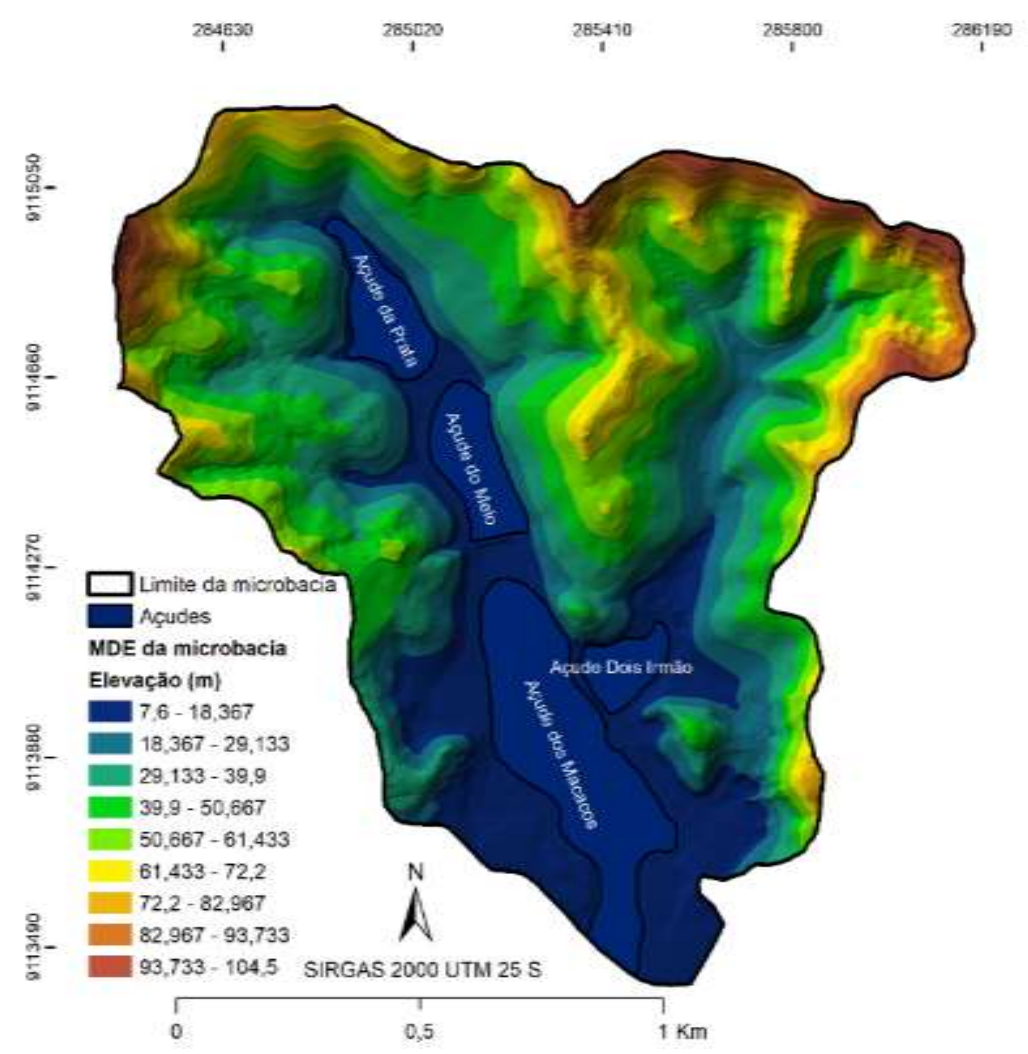

Fonte: Autores.

Wu, Li e Huang (2008) afirmam que os MDEs se apresentam como uma base de dados confiável para estudos hidrológicos. Ao estudar diferentes MDE, Cunha e Bacani (2019) constataram que a resolução espacial dos MDEs influencia diretamente nos valores dos parâmetros morfométricos.

Na Figura 7 demonstra que o padrão formado pelos cursos d'água da microbacia caracteriza-se como do tipo dendrítico, pois sua rede de drenagem assemelha-se a uma formação arborescente. Segundo Soares (2000), esse padrão ocorre em terras altas, nas quais o regolito e a rocha mãe oferecem uma resistência relativamente uniforme à erosão. Observa-se que o talvegue principal possui um comprimento de 2,02 km e declividade de 0,54\% no sentido Noroeste-Sudeste, provocando movimento da água em seu curso também neste sentido e tendo interferência direta na velocidade de escoamento. 
Figura 7. Mapa de drenagem e ordenação dos canais da microbacia do Prata.

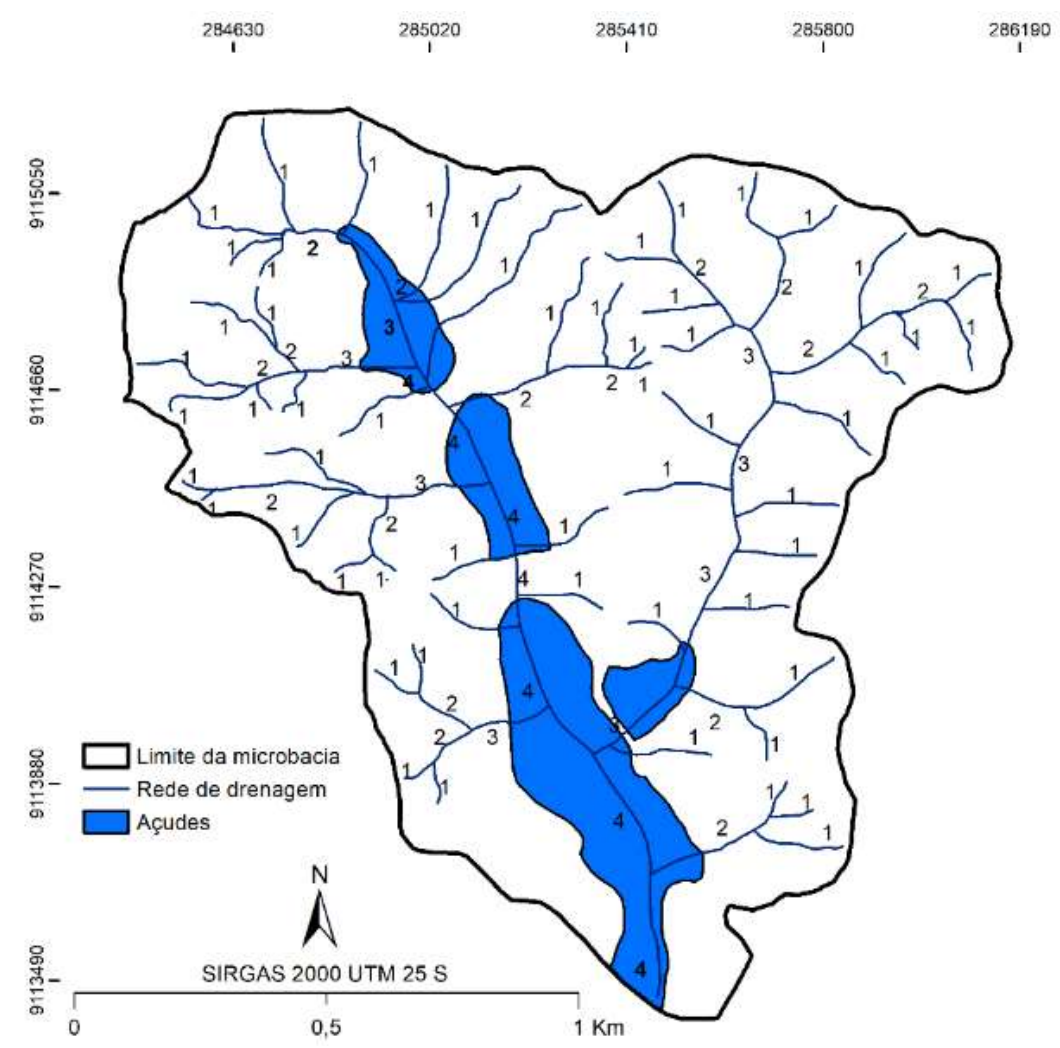

Fonte: Autores.

Quanto ao escoamento global, esta microbacia pode ser classificada como exorreica, pois é uma microbacia do Rio Capibaribe que desagua no mar. Ainda analisando a Figura 7 constatou-se, segundo a classificação de Strahler (1957), que a microbacia apresenta uma ordenação de canais de $4^{\mathrm{a}}$ ordem, condizendo com o relevo forte ondulado característico da microbacia. Quanto maior a ramificação da rede de drenagem, mais eficiente é o sistema de drenagem da bacia (Bertoni e Lombardi Neto, 2008).

A Tabela 1 apresenta os valores obtidos para a caracterização morfométrica da microbacia hidrográfica estudada. 
Tabela 1. Características morfométricas da microbacia do Prata.

\begin{tabular}{cc}
\hline Parâmetros & Valores \\
\hline Área de drenagem & $1,86 \mathrm{~km}^{2}$ \\
Rede de drenagem & $12,75 \mathrm{~km}$ \\
Perímetro & $6,48 \mathrm{~km}$ \\
Coeficiente de compacidade & 1,33 \\
Fator de forma & 0,45 \\
Índice de circularidade & 0,56 \\
Comprimento do curso d'água principal & $2,02 \mathrm{~km}$ \\
Declividade do alvéo & $0,54 \%$ \\
Ordem da bacia & $4^{\mathrm{a}}$ \\
Densidade de drenagem & $6,87 \mathrm{~km} / \mathrm{km}^{2}$ \\
Tempo de concentração (Ven Te Chow) & $48,13 \mathrm{~min}$ \\
\hline
\end{tabular}

Fonte: Autores.

A microbacia do Prata pode ser classificada, segundo Rocha (2001) como uma unidade pequena, pois sua área de drenagem e perímetro foram, respectivamente, de 1,86 km² e 6,48 km (Tabela 1). Para Tucci (2013) a potencialidade hídrica de uma bacia hidrográfica pode ser mensurada pela área de contribuição.

Pode-se afirmar que os fatores hidrológicos que ali interferem, têm grandes possibilidades de controle. Além da superfície total da microbacia, fatores que interferem na geração do deflúvio, tais como comprimento das ravinas, densidade de drenagem, índice de circularidade, fator de forma, declividade média e coeficiente de rugosidade devem ser levados em consideração para classificar uma microbacia. Segundo Moura et al (2009), as microbacias apresentam, como características distintas, alta sensibilidade tanto à chuva de alta intensidade aquelas de curta duração, como ao fator uso do solo.

O fator de forma (Ff), coeficiente de compacidade (Kc) e índice de circularidade (Ic) são números que possibilitam a determinação da forma da bacia. Segundo Villela e Mattos (1975) a determinação e associação das formas de uma bacia hidrográfica são importantes, pois auxiliam na determinação do tempo de concentração. Quanto maior o tempo de concentração, menor será a vazão máxima de enchente, se mantidas constantes as outras características.

$\mathrm{Na}$ microbacia em estudo o fator de forma, no que se refere a ocorrência de enchentes é considerado de baixa ocorrência, segundo a classificação descrita em Silva e Mello (2008), Campanharo (2010), Souza et al. (2017) e Santos et al. (2018), onde valores de $\mathrm{Ff} \geq 0,75$ são altos, 0,75 - 0,50 são médios e $\mathrm{Ff} \leq 0,50$ são de baixas tendências à ocorrência de enchentes.

O coeficiente de compacidade é médio, com valore de 1,33, onde Kc entre 1,00 - 1,25 são altos, 1,25 - 1,50 são médios e < 1,50 são baixos (Silva \& Mello, 2008; Campanharo, 2010; Souza et al., 2017 \& Santos et al., 2018). Para Santos et al. (2018) o Kc é sempre um valor > 1, se fosse 1 a bacia seria um círculo perfeito. Quanto menor o Kc, mais próximo da unidade, mais circular é a bacia, menor o Tc e maior a tendência de haver picos de enchente. Bacias que apresentaram valores de Kc superiores a 1,5 apresentam formato alongado e não estão sujeitas a enchentes em condições normais de chuva (Oliveira, Oliveira \& Crestani, 2011).

Com base no fator de forma, observa-se que a microbacia tem uma baixa tendência à enchentes. Porém, com base no coeficiente de compacidade, a microbacia apresenta média tendência à grandes enchentes. Como o primeiro expressa uma 
tendência a enchentes, sem correlacionar-se à grandeza da enchente, enquanto o segundo expressa a dimensão das enchentes, estes índices são complementares. Assim, esta microbacia apresenta tendência baixa à enchentes e se estas ocorrerem, poderão ser de médio a grande porte.

O tempo de concentração de água da chuva, com valor de 48,13 minutos, indica que esta microbacia não possui formato com tendência ao de uma circunferência, correspondendo, portanto, a uma bacia alongada, conforme verificado na Figura 7. Tal fato pode ainda ser comprovado pelo índice de circularidade, cujo valor distante da unidade, é de 0,56. Segundo Villela e Mattos (1975), as bacias alongadas possuem menor concentração do deflúvio. Considerando esta característica, podese inferir que a microbacia hidrográfica do Prata apresenta menor risco de enchentes nas condições normais de precipitação, sendo este fato corroborado com os resultados antes discutidos para os índices fator de forma e compacidade.

A densidade de drenagem obtida foi de $6,87 \mathrm{~km} / \mathrm{km}^{2}$. Com base em Villela e Mattos (1975), este índice pode variar de $0,5 \mathrm{~km} / \mathrm{km}^{2}$, para bacias com drenagem pobre, a 3,5 ou mais, para bacias excepcionalmente bem drenadas, indicando, portanto, que a microbacia em estudo apresenta excelente capacidade de drenagem. Ressalta-se que com técnicas distintas ou base de dados em diferentes escalas executando uma mesma avaliação pode-se encontrar valores um pouco diferentes para a densidade de drenagem (Carvalho, 2007).

A alta capacidade de drenagem também pode ser confirmada pelo grau de ramificação da rede de drenagem desta microbacia que é de $4^{\mathrm{a}}$ ordem, considerando-se que, quanto mais ramificada a rede, mais eficiente será o sistema de drenagem. Para Manosso (2020) a densidade de drenagem é reconhecidamente um dos mais importantes parâmetros morfométricos, por se correlacionar com diversas variáveis do meio físico, como relevo, litologia, uso e ocupação do solo.

O MDE permitiu a confecção do mapa de declividade (Figura 8) onde o menor percentual corresponde ao relevo plano, pois apesar de aparecer com valores de 25,72 hectares que correspondem a 14,05\% do total da área da microbacia (Tabela 2), aos quais estão incluídos os 22,57 hectares dos espelhos dos corpos d'água, se estes forem subtraídos ter-se-á um valor de 3,15 ha, que correspondem a aproximadamente 1,72\%. Tonello et al. (2006) afirmam que a declividade, característica que afeta consideravelmente o ciclo hidrológico de uma bacia hidrográfica, é de fundamental importância para seu planejamento e manejo. Para Sreedevi et al. (2013), é essencial a compreensão da distribuição da inclinação do relevo, uma vez que ela fornece informações para o planejamento e mecanização da agricultura, planejamento de estruturas de engenharia e práticas conservacionistas. 
Figura 8. Mapa de declividade da microbacia do Prata.

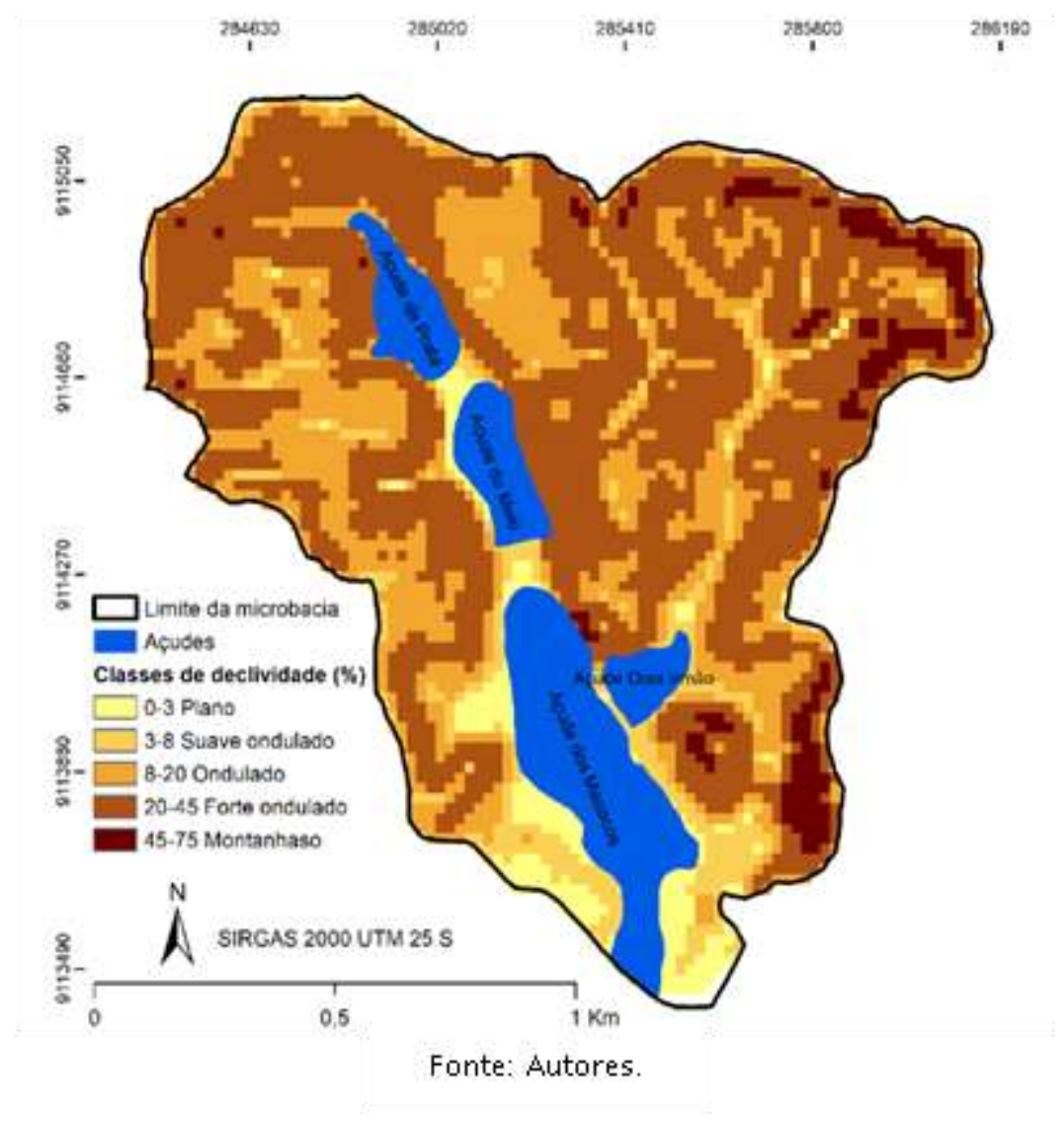

Na microbacia do Prata há o predomínio de encostas íngremes, ficando as áreas planas restritas às partes mais baixas dos talvegues (Tabela 2). Este fato mostra que apesar de ser uma área situada dentro do domínio dos sedimentos do Grupo Barreiras, houve uma forte dissecação do relevo, não caracterizando formas típicas dos denominados Tabuleiros Costeiros como mencionados em Jacomine (2001) e Rezende et al. (2002).

Tabela 2. Tipos de relevo e classes de declividade, com suas respectivas áreas na microbacia do Prata.

\begin{tabular}{cccc}
\hline \multirow{2}{*}{ Tipos de relevo } & Classes de declividade & \multicolumn{2}{c}{ Áreas } \\
\cline { 3 - 4 } & $\%$ & ha & \% \\
\hline Plano & $0-3$ & 25,72 & 14,05 \\
Suave ondulado & $3-8$ & 16,20 & 8,85 \\
Ondulado & $8-20$ & 47,48 & 25,94 \\
Forte ondulado & $20-45$ & 85,68 & 46,81 \\
Montanhoso & $45-75$ & 7,96 & 4,35 \\
\hline Total & - & 183,04 & 100 \\
\hline
\end{tabular}

Fonte: Autores.

O tipo de relevo forte ondulado é predominante com 46,81\% da área da microbacia seguido de 25,64\% referente ao relevo ondulado. Villela e Mattos (1975) assinalam a declividade como importante característica de análise de uma bacia hidrográfica, uma vez que, influencia diretamente na velocidade de escoamento superficial das águas das chuvas, que por sua 
vez correlacionam-se com os picos de enchente, infiltração e susceptibilidade para erosão dos solos. Além disso, Tonello et al. (2006) e Santos et al. (2012) consideram que as características do relevo podem influenciar na quantidade de radiação que a bacia hidrográfica recebe e, consequentemente, na evapotranspiração, na temperatura e na precipitação.

\section{Qualidade físico-química e microbiológica}

$\mathrm{O}$ pH governa as propriedades solventes da água e os processos físicos, químicos e biológicos que ocorrem no corpo d’água, em geral para águas naturais está entre 6,0 e 9,0. Nas águas dos reservatórios do Prata, os valores de pH estiveram entre o intervalo de 3,76 a 6,84 (Gráfico 1). Segundo Cunha et al. (2020), resultados dessa magnitude podem ser justificados em função de que o pH é alterado pelas concentrações de íons H+ originados da dissociação do ácido carbônico, que geram baixos valores de pH. Esse ácido carbônico, nos corpos d'água, é resultante, segundo Neto et al. (2017), da introdução de gás carbônico pelas águas de chuva, ar atmosférico, matéria orgânica do solo e, principalmente, matéria orgânica que é consumida e oxidada nas águas. Estudos realizados, nos açudes do Prata e do Meio, por Araújo e Oliveira (2011) demonstraram um valor de pH médio de caráter levemente ácido para os dois reservatórios.

Gráfico 1. Variação do pH em função do tempo nos açudes do Prata e do Meio.

$\mathrm{PH}$

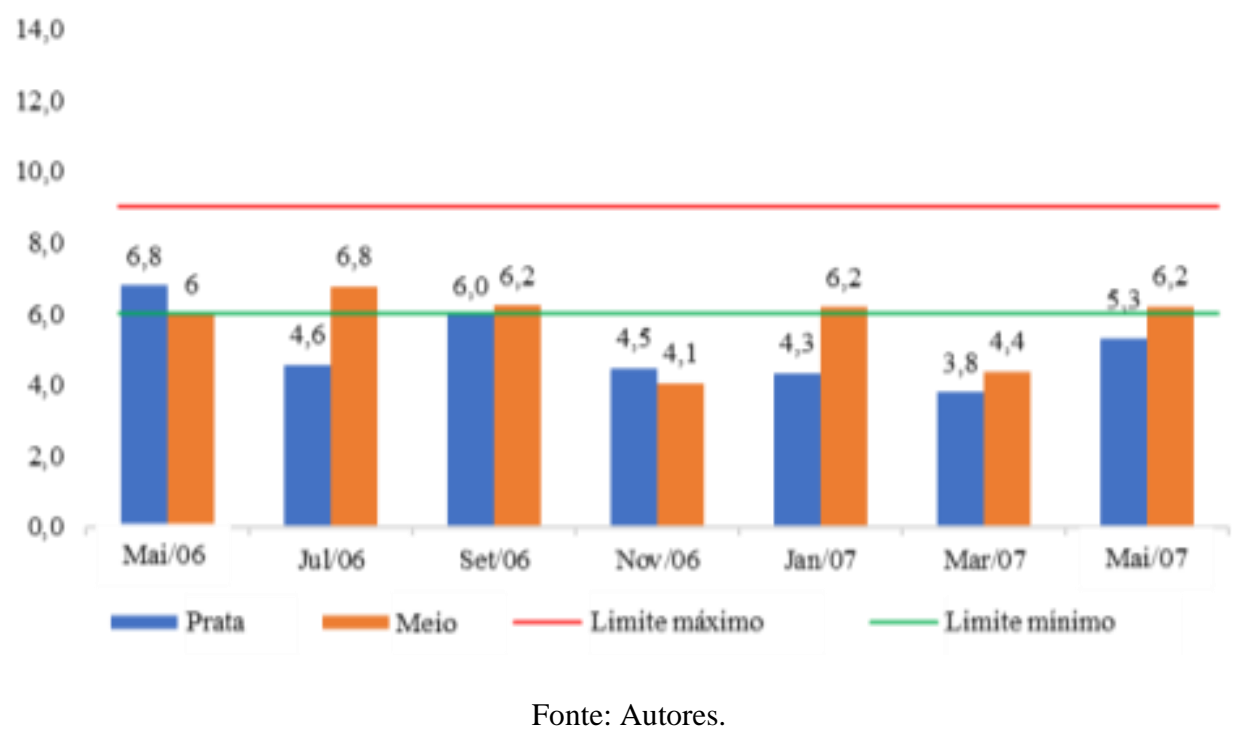

Em geral os valores de OD estiveram abaixo de 6mg/L (Gráfico 2) - valor mínimo indicado pela Resolução do CONAMA n³57 para águas doces Classe 1 - provavelmente devido ao aumento do aporte de matéria orgânica, carreada pela água de enxurrada. Araújo e Oliveira (2011) encontraram valores de oxigênio dissolvidos nos pontos do açude do Prata e do Meio onde apresentava um melhor aspecto marginal entre de 7,6 mg/l e 5,1 mg/l respectivamente, corroborando com os valores obtidos. 
Gráfico 2. Variação do oxigênio dissolvido (OD) em função do tempo nos açudes do Prata e do Meio.

OD

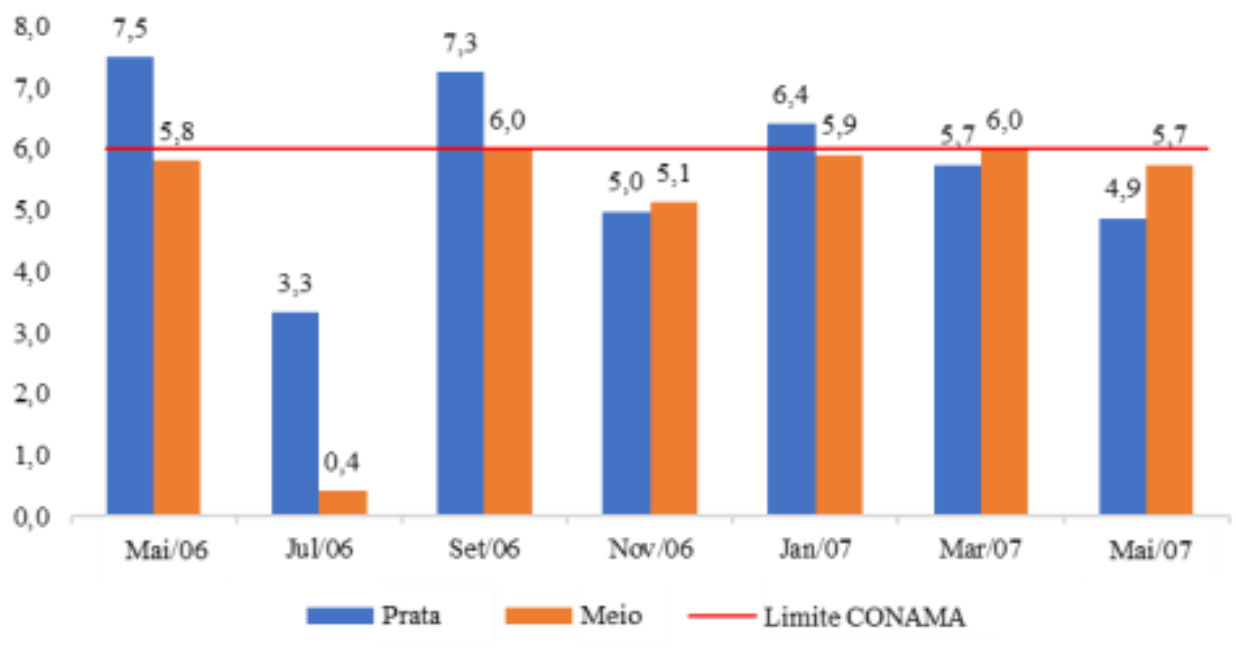

Fonte: Autores.

De acordo com o CONAMA, para classe Especial, como é o caso dos corpos d'água estudados, os valores de DBO permitidos pela legislação, seria de $3 \mathrm{mg}$ de $\mathrm{O}_{2} \cdot \mathrm{L}^{-1}$, sendo esse valor superado somente pelo açude do Prata na última coleta chegando a 4,05 mg de $\mathrm{O}_{2}$ (Gráfico 3). Esses valores indicam aumento na concentração de matéria orgânica no corpo d'água, no entanto esse acréscimo de matéria orgânica ainda não está influenciando nas concentrações de oxigênio dissolvido.

Para Araújo e Oliveira (2011) o teste de DBO é determinante das atividades de controle a serem tomadas em casos de poluição dos corpos da água, sendo de grande importância para avaliar a capacidade de purificação de corpos hídricos.

Gráfico 3. Variação da DBO em função do tempo nos açudes do Prata e do Meio.

DBO

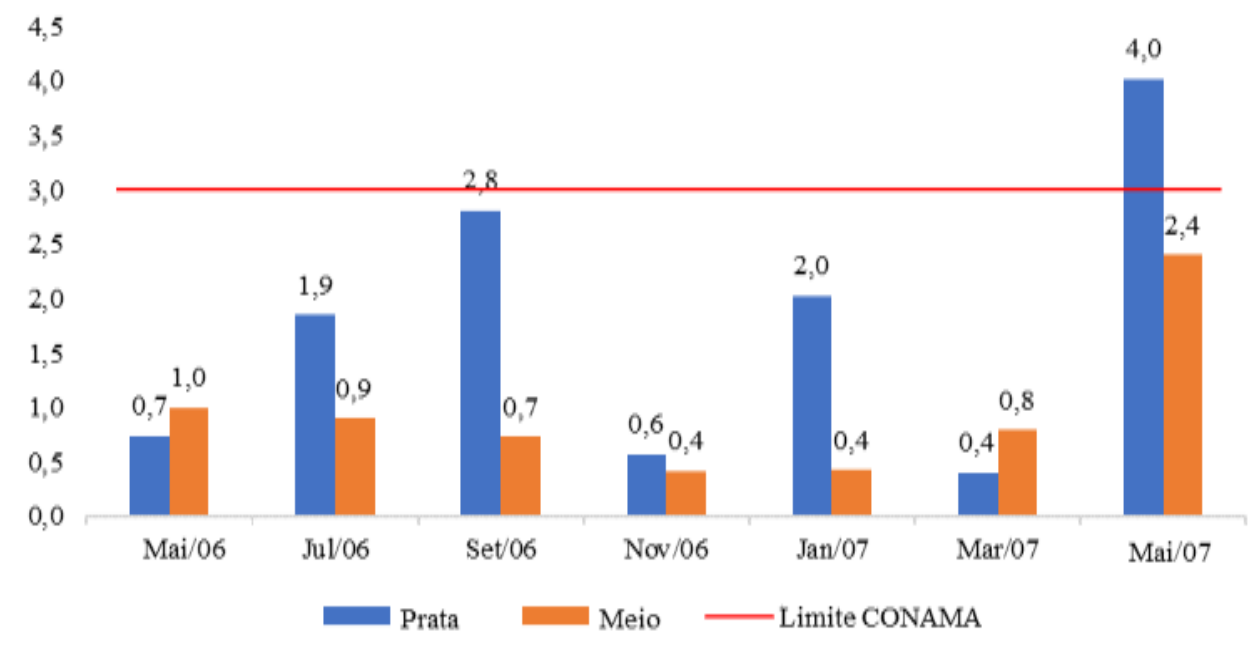

Fonte: Autores.

De acordo com os dados de coliformes totais e fecais obtidos nas análises das águas dos reservatórios do Prata e Meio (Tabela 3), todas as amostras analisadas durante o período de monitoramento apresentaram contaminação pelos dois grupos de bactérias, sendo consideradas insatisfatórias para o consumo humano segundo a Portaria 518/2004 do Ministério da Saúde e 
por encontrarem-se acima dos padrões do CONAMA para potabilidade. Dessa forma, torna-se necessário tratamento de desinfecção para sua utilização.

Tabela 3. Resultados das análises microbiológicas de Coliformes Totais (CT)

e Fecais $(\mathrm{CF})$ em NMP/100mL.

\begin{tabular}{cccccc}
\hline \multirow{2}{*}{ MÊS } & Ano & \multicolumn{2}{c}{ PRATA } & \multicolumn{2}{c}{ MEIO } \\
\cline { 3 - 6 } & & 150 & 120 & 300 & 160 \\
\hline Mai & & CT & CF & CT & CF \\
Jul & 220 & 30 & 1600 & 300 \\
Set & & 1600 & $<2$ & 1600 & 900 \\
Nov & & 110 & 7 & 30 & 13 \\
Jan & & 240 & 4 & 170 & 13 \\
Mar & 2007 & 1600 & 23 & 500 & 23 \\
Mai & 170 & 140 & 900 & 140 \\
\hline
\end{tabular}

Fonte: Autores.

Apesar de estarem localizados em área de proteção ambiental, possivelmente esta contaminação deve-se ao fato da ação antrópica exercida pela população nos arredores da Unidade de Conservação. Ressalta-se a importância do acompanhamento e monitoramento contínuo da qualidade das águas de forma a verificar as condições de conservação e uso dos reservatórios da microbacia.

A água do Açude do Prata é tão limpa que passa por apenas um dos três estágios de tratamento empregados pela Companhia Pernambucana de Saneamento (COMPESA) antes de alcançar as torneiras das casas de 47 mil recifenses. Pesquisadores supõem que essa pureza se deve ao manancial estar numa área protegida: o Parque Dois Irmãos (APAC, 2011)

\section{Ação antrópica}

A microbacia do Prata compreende uma área de $1,86 \mathrm{~km}^{2}$, dos quais $23,24 \%$ estão ou estiveram sob a influência da ação antrópica, distribuídos em 12,16\% com espelho d'água e 11,28\% área ocupada pelo Zoológico. Há que se computar ainda, as áreas das estradas e trilhas que existem no interior da mata.

Os açudes existentes são frutos da construção de barramentos no principal talvegue da microbacia, realizados na primeira metade do século XIX (Silvestre, Carvalho \& Van den Berg, 1998), sobre o qual existia um córrego permanente, com água oriunda de um “olho d'água”. Desta forma, percebe-se que a microbacia do Prata, mesmo pertencendo a uma área de preservação ambiental, recebe interferências diretas de ações planejadas.

No interior da mata, nota-se a existência de trincheiras que, segundo informações dos guias, constituíam-se em espaço para os treinamentos de soldados durante a $2^{\mathrm{a}}$ Guerra Mundial. Na parte sudeste do Parque, quase no seu limite, existe uma elevação com quase $80 \mathrm{~m}$ de altura conhecida como "Chapéu do Sol”, onde existe um grande túnel, que segundo informações de guias, tem comunicação com a praia de Maria Farinha. 
No interior da microbacia, a pressão exercida sobre o ecossistema é caracterizada, de certa forma, devido à existência de um zoológico que é frequentado por pessoas durante todos os dias da semana. Na sua porção leste, há uma falésia que a protege do acesso de pessoas não autorizadas, enquanto na sua porção norte o próprio limite com a outra parte do Parque constitui-se num obstáculo aos que, porventura, tentarem entrar no mesmo.

O principal problema está na sua porção oeste, que apesar de ter uma pequena parte sendo limítrofe com a Universidade Federal Rural de Pernambuco (UFRPE), grande extensão está limitada com áreas urbanas, muitas vezes caracterizadas por invasões com ocupações desordenadas, como pôde ser observado durante o caminhamento no campo como evidenciado na Figura 9.

Figura 9. Ocupação urbana desordenada no limite oeste da microbacia do Prata

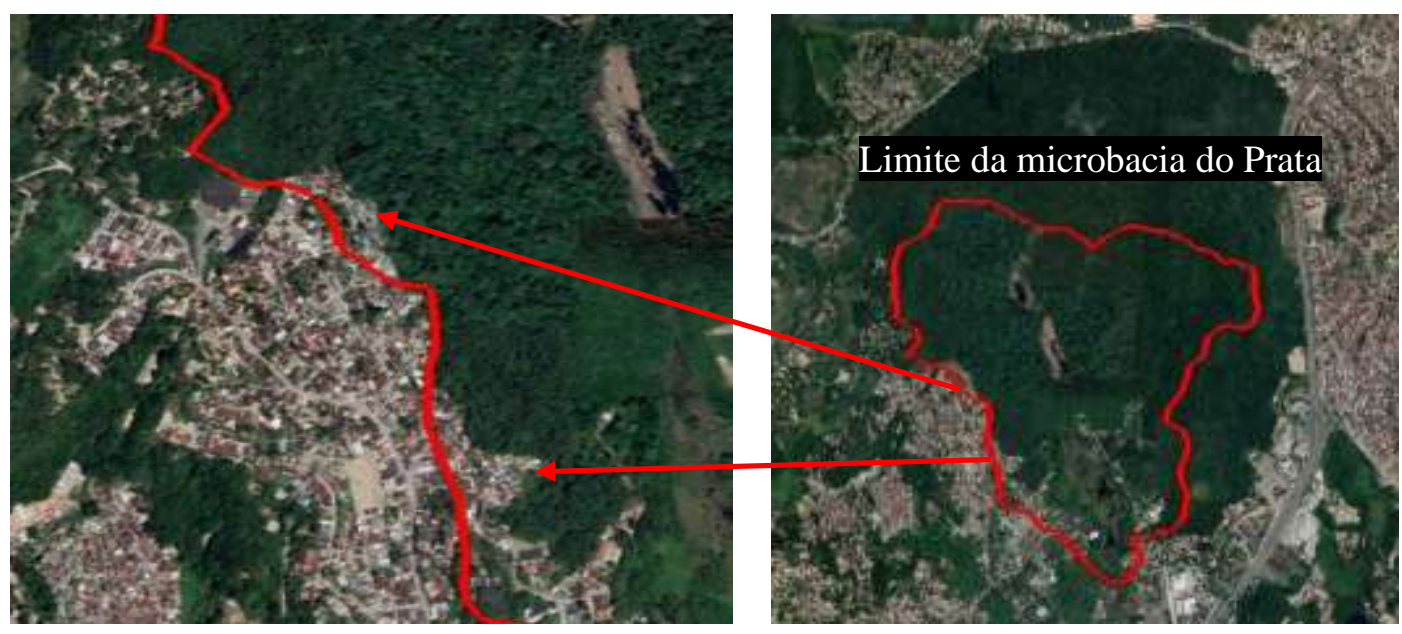

Fonte: Autores.

Neste caso, muitas pessoas que ali habitam, frequentam a periferia do Parque, como pode ser constatado através de lixo ou mesmo dejetos humanos nas trilhas (Figura 10). Some-se a isto, o fato de que o baixo poder aquisitivo de muitos que ali residem, os força a retirar lenha, de forma ilegal, do Parque para em fogões artesanais cozinhar os seus alimentos. É visível que há retirada da vegetação local para uso doméstico da madeira, e que nas encostas íngremes, com solos susceptíveis à erosão, resulta num agravamento da degradação deste recurso natural, o que torna o ambiente cada vez mais ameaçado.

Nestas áreas, percebeu-se durante as incursões ao campo que a mata é mais rala e que o processo de erosão, às vezes se faz presente. Outro aspecto merecedor de destaque é a ausência de animais, particularmente mamíferos.

Estes fatos não mais corroboram com a afirmação de Coutinho et al. (1998), pois afirmaram que a microbacia do Prata é um dos poucos ecossistemas lacustres da região metropolitana do Recife sem influência da ação antrópica, onde as condições ambientais permanecem em seu estado natural. 
Figura 10. Evidências de ações antrópicas desordenadas como desmatamento de encostas e descarte incorreto de lixo na área da microbacia do Prata.

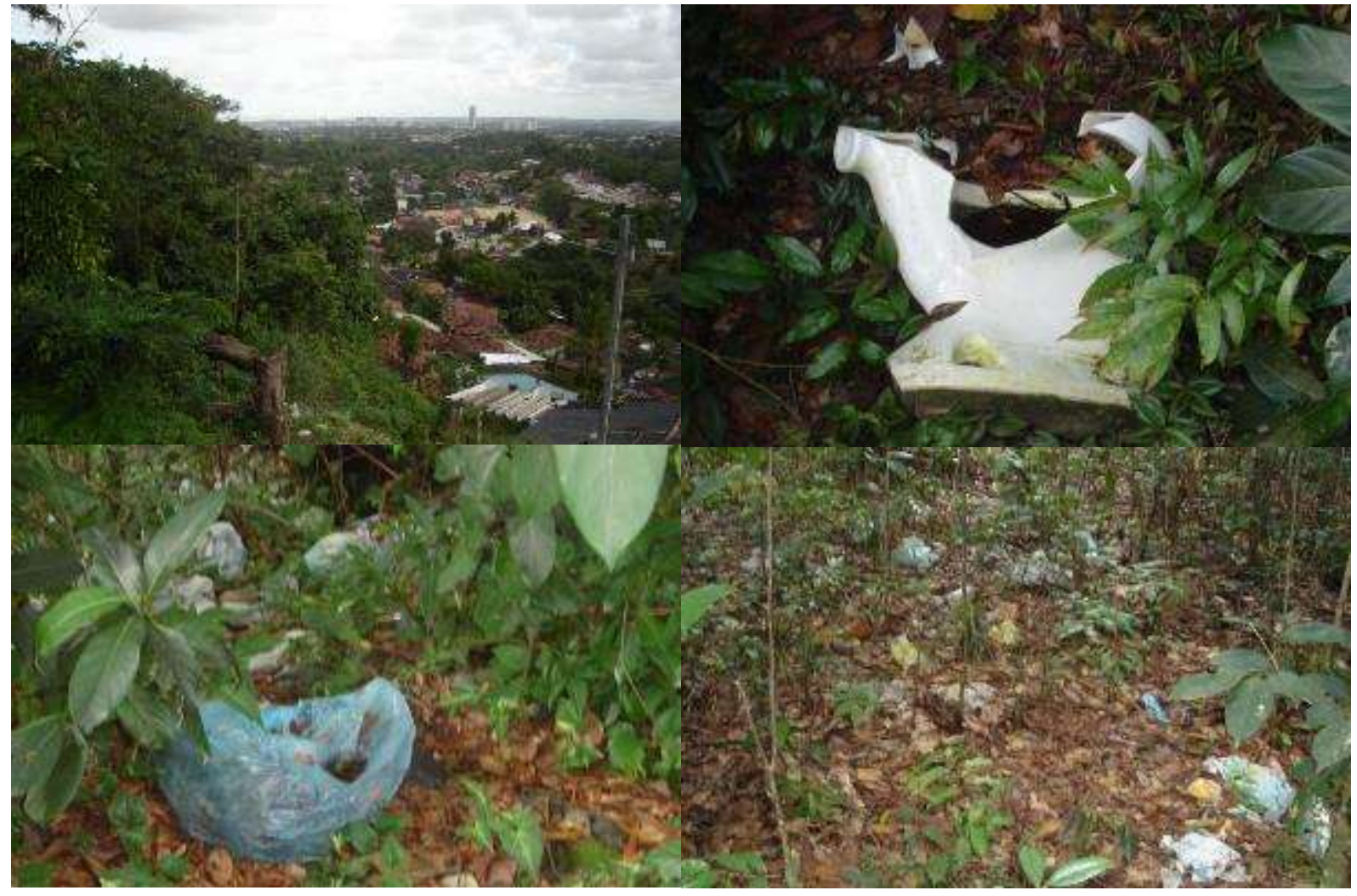

Fonte: Autores

Como uma medida mitigadora, poder-se-iam criar projetos de educação ambiental, em que a população poderia ser orientada e participar efetivamente na proteção ao Parque. Ressalta-se que a cobertura vegetal desta área, representada por um remanescente de Mata Atlântica, contribui para a manutenção do solo e da quantidade e qualidade da água deste manancial.

Mesmo tratando-se de um Parque Estadual, sujeito a leis rígidas de proteção ambiental, há que se cuidar para os que ali transitam, sejam pesquisadores ou visitantes, obedeçam às normas de preservação e conservação, pois entre outras imposições, o relevo e a condição do solo em muitas situações caracterizam ambientes frágeis.

\section{Conclusão}

O MDE gerado contribuiu para a delimitação da microbacia hidrográfica, definição da drenagem e elaboração do mapa de declividade.

A microbacia do Prata é de $4^{\circ}$ ordem e apresenta baixa tendência à enchentes e se estas ocorrerem, poderão ser de médio a grande porte.

Houve predomínio da classe de 20 - 45\% de declividade, totalizando quase 50\% da área da microbacia.

Durante o período monitorado a qualidade das águas dos dois reservatórios se encontraram fora dos padrões de potabilidade, sendo necessário tratamento de desinfecção para seu consumo.

O relevo e a condição do solo caracterizam a fragilidade do ambiente, o que demanda medidas de fiscalização mais rigorosas a serem adotadas para que se obedeçam às normas de preservação e conservação.

Devido a forte pressão antrópica, com a ocupação urbana desordenada e descarte irregular de lixo, propõem-se medidas mitigadoras, como a criação de projetos de educação ambiental, para orientar a população e incentivar a participação 
efetiva na proteção ao Parque.

\section{Agradecimentos}

À CAPES pela concessão da bolsa de mestrado, ao Programa de Pós Graduação em Engenharia Agrícola e Ambiental da UFRPE, à Pró Reitoria de Extensão, Cultura e Cidadania da UFRPE pelas bolsas de extensão, ao Grupo de Política de Uso do Solo (POLUS).

\section{Referências}

APAC. Agência Pernambucana De Águas E Clima. (2011). Pesquisa avalia influência de parque em qualidade da água. Jornal do Comércio. Recife.

APHA. American Public Health Association. (2005). American Water Works Association and Water Pollution Control Federation, Standard Methods for the Examination of Water and Wastewater, 21 st Edition.

Araujo, R. C. da S., \& Oliveira, F. H. P. C. de. (2011). Análise De Parâmetros Limnológicos Da Água Dos Açudes Do Prata E Do Meio (Pernambuco-Brasil). In XIX Simpósio Brasileiro de Recursos Hídricos (pp. 1-19).

Bagatini, T., Cogo, N. P., Gilles, L., Portela, J. C., Portz, G., \& Queiroz, H, T. (2011). Perdas de solo e água por erosão hídrica após mudança no tipo de uso da terra, em dois métodos de preparo do solo e dois tipos de adubação. Revista Brasileira de Ciência do Solo, 35, 999-1011.

Bertoni, J., \& Lombardi Neto, F. (2008). Conservação do solo. Ícone, São Paulo. (6 ${ }^{\mathrm{a}}$ ed.) 355p.

Boldajia, M. N., \& Kellerb, T. (2016). Degree of soil compactness is highly correlated with the soil physical quality index S. Soil and Tillage Research, 159, 41-46.

Braga, S. E., Caldas, A. M., Rizzi Neto, E., Silva, L. J. de S., Perônico, A. M. B. L., Wanderley, R. A., Freitas, P. M. L. de., Lima, J. R. de., Cunha, C. R. R. O. da., \& Abreu, B. S. (2021). Environmental conflict of land use in Tapacurá-PE hydrographic basin. Research, Society and Development, 10(2), e52310212833. https://doi.org/10.33448/rsd-v10i2.12833

Braga, S. E., Wanderley, R. A., Holanda, T. F., \& Caldas, A. M. (2020). Aplicação da Análise Hierárquica para mapeamento de risco de inundação: O caso no município de Limoeiro (Pernambuco - Brasil). Meio Ambiente (Brasil), 2(1), 57-66. https://doi.org/10.5281/zenodo.3969577

Campanharo W. A. (2010). Diagnostico físico da bacia do rio Santa Maria do Doce-ES. Monografia. Departamento de Engenharia Florestal da Universidade Federal do Espírito Santo

Carvalho D. F., Mello J. L. P., \& Silva L. D. B. (2007). Apostila de Irrigação e Drenagem. Universidade Federal Rural do Rio de Janeiro, Seropédica - RJ

Christofoletti, A. (1999). Modelagem de sistemas ambientais. Edgar Blücher, (1ª ed.) 200p.

Christofoletti, A. (1970). Análise morfométrica de bacias hidrográficas no Planalto de Poços de Caldas. 375f. Tese (Livre Docência), Instituto de Geociências - Universidade Estadual Paulista, Rio Claro.

CONAMA. Conselho Nacional De Meio Ambiente. Resolução nº 357 de 17 de março 2005. Brasília.

Correa, R. dos S., Fernandes, L. L., \& Santana, L. R. (2020). Estudo da viabilidade econômica com o aproveitamento de água de chuva numa metrópole da Amazônia, Brasil. Research, Society and Development, 9(9), e865997985. https://doi.org/10.33448/rsd-v9i9.7985

Coutinho, R. Q., Lima Filho, M. F., Souza Neto, J. B., \& Silva, E. P. (1998). Características climáticas, geológicas, geomorfológicas e geotécnicas da Reserva Ecológica de Dois Irmãos. In: Machado, I. C., Lopes, A. V., \& Pôrto K. C. Reserva Ecológica de Dois Irmãos: estudos em um remanescente de Mata Atlântica em área urbana (Recife-Pernambuco-Brasil). Recife: Secretaria de Ciência, Tecnologia e Meio Ambiente - SECTMA - Ed. Universitária, da UFRPE. 326p.

Cunha, E. R., \& Bacani, V. M. (2019). Influência da resolução do MDE na caracterização morfométrica de bacia hidrográfica, Caderno de Geografia, 29(59). https://doi.org/10.5752/P.2318-2962.2019v29n59p1029

Cunha, G. D., Castro, D. B., Santos, A. V., Caramello, N. D. A., Stachiw, R., \& Tronco, K. M. Q. (2020). Qualidade da água de poços em Rolim de Moura do Guaporé, Rondônia. Revista Brasileira de Ciências da Amazônia, 9(2), 1-9. https://doi.org/10.47209/2317-5729.v.9.n.2.p.1-9

Duarte, C. C., Galvíncio, J. D., Corrêa, A. C. B., \& Araújo, M. S. B. (2007). Análise fisiográfica da bacia hidrográfica do rio Tapacurá- PE. Revista de Geografia. Recife: UFPE - DCG/NAPA, 24(2).

EMBRAPA. Empresa Brasileira De Pesquisa Agropecuária. (1988). Serviço Nacional de Levantamento e Conservação de Solos. Critérios para distinção de classes de solos e de fases de unidades de mapeamento: normas em uso pelo SNLCS. Rio de Janeiro. 67p. (Documentos EMBRAPA/ SNLCS, 11).

Ferreira, F. A. O., Franco, A. C. S., \& Souza, J. C. (2020). Caracterização geomorfométrica e pedológica da bacia hidrográfica do rio Bagagem (GOIÁS GO). Revista de Geografia (Recife) 37(2).

Fraga, M. S., Ferreira, R. G., Silva, F. B., Vieira, N. P. A., Silva, D. P., Barros, F. M., \& Martins, I. S. B. (2014). Caracterização Morfométrica da Bacia Hidrográfica do Rio Catolé Grande, Bahia, Brasil. Nativa, 2, 114-118. 
Gonçalves, C. S., Rheinheimer, D. S., Pellegrini, J. B. R., \& Kist, S. L. (2005). Qualidade da água numa microbacia hidrográfica de cabeceira situada em região produtora de fumo. Revista Brasileira de Engenharia Agrícola e Ambiental, Campina Grande, 9(3), $391-399$.

Jacomine, P. K. T. (2001). Evolução do conhecimento sobre solos coesos no Brasil. In.; Cintra, F. L. D., Anjos, J. L., Ivo, W. M. P., Coesão em solos dos tabuleiros costeiros. Anais. Aracaju, EMBRAPA Tabuleiros Costeiros. 339 p.

Khanday, M. Y., \& Javed, A. (2017) Hydrological investigations in the semi-arid Makhawan watershed, using morphometry. Appl Water Sci.

Leal, M. S., \& Tonello, K. C. (2017). Análise da morfometria e do uso e cobertura da terra da microbacia do Córrego Ipaneminha de baixo, Sorocaba/SP. Floresta, 46(4), 439-446.

Manosso, F. C. (2020). Parâmetros morfométricos de bacias hidrográficas situadas sobre a Formação Serra Geral, estado do Paraná, Brasil. Caderno de Geografia, 30(62), 753. https://doi.org/10.5752/p.2318-2962.2020v30n62p753

Moraes, A. C. R. (1993). Configuração de metodologia para o macrozonemamento costeiro do Brasil. Brasília: M.M.A/IBAMA. 51 p. Relatório final

Moraes, M. T., Debiasi, H., Franchini, J. C., \& Silva, V. R. (2012). Correction of resistance to penetration by pedofunctions and a reference soil water content. Revista Brasileira Ciência do Solo, 36, 1395-1406.

Moura, A. E. S. S. de., Correa, M. M., Silva, E. R. da., Ferreira, R. L. C., Figueiredo, A. de C., \& Possas, J. M.C. (2009). Interceptação das chuvas em um fragmento de floresta da Mata Atlântica na Bacia do Prata, Recife, PE. Revista Árvore, 33 (3), 461-469. https://doi.org/10.1590/s0100-67622009000300008

Neto, W. R. N., Pereira, D. C. A., Santos, J. R. N., Monteiro, A. S., Villis, P. C. M., \& Fillho, V. E. M. (2017). Análise da potabilidade das águas dos poços rasos escavados da comunidade do Taim em São Luís - Maranhão. Águas Subterrâneas, 31(3), 272. https://doi.org/10.14295/ras.v31i3.28869

Oliveira, E. D. de., Oliveira, E. D. de., \& Crestani, A. (2011). Caracterização fisiográfica da Bacia de drenagem do Córrego Jandaia, Jandaia do Sul/PR. ACTA Geográfica, 5(10), 169-183. 10.5654/actageo2011.0510.0010

Pissarra, T. C. T., Politano, W., \& Ferraudo, A.S. (2004). Avaliação de características morfométricas na relação solo-superfície da bacia hidrográfica do córrego Rico, Jaboticabal (SP). Revista Brasileira Ciência do Solo, 28, 297-305.

RECIFE, Prefeitura da Cidade do. (2000). Atlas ambiental da cidade do Recife. Recife: SEPLAM. 151p.

Rezende, J. O., Magalhães, A. F. J., Shibata, R. T., Rocha, E. S., Fernandes, J. C., Brandão, F. J. C., \& Rezende, V. J. R. P. (2002). Citricultura nos solos coesos dos Tabuleiros Costeiros: análise e sugestões. Salvador: SEAGRASPA, 97p. (Série Estudos Agrícolas; 3 ).

Rocha, J. S. M. da., \& Kurtz, S. M. de J. M. (2001). Manual de Manejo Integrado de Bacias Hidrográficas 4. ed. - Santa Maria: Edições UFSM CCR/UFSM. 302 p. tab., gráfs., il.

Rodrigues, J. G. V., Moreira, S. A., \& Freire, E. M. X. (2021). Relevância e estratégias para viabilização da criação de corredores ecológicos em área da Mata Atlântica setentrional. Revista Brasileira de Políticas Públicas, 10(3). https://doi.org/10.5102/rbpp.v10i3.6624

Santos, A. M. D., Targa, M. D. S., Batista, G. T., \& Dias, N. W. (2012). Morphometric analysis of sub-basins Fojo and Perdizes in the city of Campos do Jordão, SP, Brazil. Revista Ambiente \& Água, Taubaté, 7(3), 195-211.

Santos, D. B. dos., Vidotto, M. L., Bertinatto, R., Marcon, G. R. de S., \& Frigo, E. P. (2012). Caracterização morfométrica da bacia hidrográfica do Rio São José, Cascavel, PR. Revista Brasileira de Tecnologia Aplicada nas Ciências Agrárias, Guarapuava, 5(2), 7-18.

Santos, G., Silva, A. A., Braz, A. R. C., \& Carneiro, F. M. (2018). Caracterização morfométrica das bacias hidrográficas inseridas no município de Rio Verde, Goiás, como ferramenta ao planejamento urbano e agrícola. Geografia, Ensino e Pesquisa, Santa Maria-MS, 22(17), 01-13.

Silva, A. M., \& Mello, C. R. (2008). Apostila de hidrologia. 133p. Universidade Federal de Lavras, Lavras.

Silva, D. C. C., Albuquerque Filho, J. L., Sales, J. C. A., \& Lourenço, R. W. (2016). Uso de indicadores morfométricos como ferramentas para avaliação de bacias hidrográficas. Revista Brasileira de Geografia Física, v.9, n.2, p.221-217.

Silva, E. M. F., Bender, F., Silva de Mónaco, M. L., Smith, A. K., Silva, P., Buckeridge, M. S., Elbl P., \& Locosselli, G. M. (2019). Um novo ecossistema: Florestas urbanas construídas pelo Estado e pelos ativistas. Estudos Avancados, 33 (97), 81-101. https://doi.org/10.1590/s0103-4014.2019.3397.005

Silva, L. F. N., Fontes, M. S. G. de C., \& Faria, J. R. G. de. (2019). Microclimas em florestas urbanas: uma revisão de literatura. Revista Nacional de Gerenciamento de Cidades, 7 (51). https://doi.org/10.17271/2318847275120192152

Silvestre, A. N., Carvalho, P. V., \& Van den Berg da C. (1998). Bacia do Prata: Aspectos qualitativos da água. In: Reserva Ecológica de Dois Irmãos: Estudo s em um Remanescente de Mata Atlântica em Área Urbana, Machado, I., Lopes, A., Porto, K. (editores). Recife, Editora Universitária UFPE. p. 51-64.

Soares, J. V. (2000). Curso de introdução à hidrologia florestal. INPE: São José dos Campos-SP. 78p.

Souza, C. F. de., Pertille, C. T., Schramm Corrêa, B. J., \& Vieira, F. S. (2018). Caracterização morfométrica da bacia hidrográfica do rio Ivaí - Paraná. Geoambiente On-Line, (29). https://doi.org/10.5216/revgeoamb.v0i29.50602

Sreedevi, P. D., Sreekanth, P. D., Khan, H. H., \& Ahmed, S. (2013). Drainage morphometry and its influence on hydrology in a semi-arid region: Using SRTM data and GIS. Environmental Earth Science, 70(2), 839-848.

Strahler, A. N. (1957). Quantitative analysis of watershed geomorphology. American Geophysical Union, 38(6), 913-920. 
Research, Society and Development, v. 10, n. 5, e12210514656, 2021

(CC BY 4.0) | ISSN 2525-3409 | DOI: http://dx.doi.org/10.33448/rsd-v10i5.14656

Tonello, K. C., Dias, H. C. T., Souza, A. L. D., Ribeiro, C. A. A. S., \& Leite, F. P. (2006). Morphometric characteristics of Cachoeira das Pombas watershed, Guanhães-MG, Brazil. Revista Árvore, Viçosa, 30(5), 849-857.

Tucci, C. E. M. (2013). Hidrologia Ciência e Aplicação: Editora da Universidade (UFRGS), ABRH: EDUSP. v. 4.

UNESCO. Relatório Mundial das Nações Unidas sobre Desenvolvimento dos Recursos Hídricos. (2016). - Água e Emprego - Fatos e números. Perugla/Itália: UNESCO no Brasil (em Brasilia) / Agência Nacional de Águas (ANA) do Brasil. P 12.

Villela, S. M., Mattos, A. (1975). Hidrologia aplicada. (1ª ed.): McGraw-Hill do Brasil. 245p.

Vörösmarty,C. J., McIntyre, P. B., Gessner, M. O., Dudgeon, D., Prusevich, A., Green, P., Glidden, S., Bunn, S. E., Sullivan, C. A., Reidy Liermann, C., \& Davies, P. M. (2010). "Global Threats to Human Water Security and River Biodiversity", in Nature, 467(7.315), 555-61.

Wu, S., Li, J., \& Huang, G. H. (2008). A study on DEM-derived primary topographic attributes for hydrologic applications: sensitivity to elevation data resolution. Applied Geography, 28(3), 210-223.

Young, G., Demuth, S., Mishra, A., \& Cudennec, C. (2014). Hydrological Challenges and Water Security: an Overview, in Hydrological Sciences and Water Security: Past, Present and Future. Proceedings of the 22th FOUACS Collegium. Paris, June, IHHS Publ., pp. 2-9. 